\title{
The Research Progress of Immunomodulatory Peptides
}

\author{
Jie Xing ${ }^{1, a}$, Mingdi Zhang ${ }^{1, b}$, Songyi Lin ${ }^{1, C^{*}}$ \\ ${ }^{1}$ Jilin University College of Food Science and Engineering, Changchun, 130062, China \\ a email: xingjie0014@163.com, bemail: zhangmd@jlu.edu.cn, cemail:linsongyi730@163.com
}

Keywords: Immunomodulatory Peptides; Preparation; Mechanism

\begin{abstract}
Immunomodulatory peptides play an important role in immune response. Researchers acquired activity peptides from natural food protein by enzymatic hydrolysis and the most commonly used enzymes are Alcalase. In this paper, the mechanism of immunomodulation was summarized briefly. The peptides charge, hydrophobicity and the length of peptide chain have great influences on the immunomodulating activities of peptides.
\end{abstract}

\section{Introduction}

It has been reported that more than 1500 different bioactive peptides were found and more than 1250 peptides with different functional significances [1], immunomodulatory peptides was one of them. These bioactive peptides could be used for anti-oxidative, antifungal, antithrombotic, sensory physiological activities and can enhance the nutritional value of food [2]. Immunomodulatory peptides modulate [3] the immune response through improving the antibody production of secretory lgA and epithelial barrier function, modulating apoptosis and TLR4 binding, inducing regulatory T cells and B cells, and controlling cytokine production. The immunomodulatory peptides generated from natural sources usually have varieties of functions but not only for immunomodulatory. Peptide fraction from the larvae of Musca domestica not only has the ability of immunomodulatory, but also plays an important role in anti-tumor [4]. Dipeptidyl peptidase 4 inhibitors could stimulate the immune system 1 and 2 and also be used in the treatment of type 2 diabetes mellitus [5]. It has reveal immunomodulatory peptides not only for immunoregulation, but also could be used for other fields.

\section{Preparation of immunomodulatory peptides}

\section{Enzymatic hydrolysis.}

Since Jolles acquired a sort of immunomodulatory peptides from milk protein by trypsin for the first time [6], a growing number of people have paid attention to generate peptides from natural sources such as milk, grain and shark meat. It was focused on the use of by-products of food protein bio-processing for immunomodulatory peptides which could enhance the production value and reduce the cost of waste disposal [7]. Immunomodulatory peptides show no activity when contained with the whole protein sequence, but can be released by enzymatic proteolysis. The enzymes used for hydrolysis could be divided into digestive system or microbial origin [8]. Microbial fermentation and food processing could also be used for producing immunomodulatory peptides separated from enzymatic proteolysis. As shown in Table 1, several enzymes had been successfully applied to hydrolysis kinds of natural protein sources to acquire bioactive peptides like whey protein, soy protein, corn protein, oyster protein. It can be found that from these data, the most common enzymes are Alcalase, trypsin and pepsin. The immunomodulatory peptides generated by enzymatic hydrolysis in vitro probably be absorbed more effectively than released from dietary proteins during the digestive process in the gut [9]. In recent years, food-hydrolyzed peptides enriched were added to immunomodulatory diets, like whey- hydrolyzed peptides enriched used to prevent fibrosis. 
Table 1 Immunomodulatory peptides derived from sources

\begin{tabular}{cccccccc}
\hline \multirow{2}{*}{ Source of peptides } & \multicolumn{5}{c}{ Conditions } & \multirow{2}{*}{ Indicator } & References \\
\cline { 2 - 5 } & enzymes & $\mathrm{pH}$ & $\mathrm{T} /{ }^{\circ} \mathrm{C}$ & Time/min & & \\
\hline \multirow{2}{*}{ Labeorohita roe } & Pepsin & 2 & 37 & 120 & & \\
& Trypsin & 8 & 37 & 150 & ABCDEF & {$[10]$} \\
Alaska pollock frame protein & Alcalase & 8 & 55 & 180 & & \\
Whypsin & 8 & 20 & 290 & $\mathrm{~A}$ & {$[11]$} \\
Soy proteins & Alcalase & 8 & 50 & - & $\mathrm{A}$ & {$[12]$} \\
Oysters protein & Alcalase & 8 & 60 & 225 & $\mathrm{AB}$ & {$[13]$} \\
& Protease & 7.5 & 50 & 300 & ABC & {$[14]$} \\
Corn protein & Alkaline & 8.5 & 55 & 180 & & \\
Green microalga & Neutral & 7 & 45 & 120 & $\mathrm{G}$ & {$[15]$} \\
\hline
\end{tabular}

A-splenic lymphocyte proliferation, B-phagocytosis capacity of peritoneal macrophages, C-natural killer (NK) cell activity, D-splenic $\mathrm{T}$ lymphocyte, E-small intestine mucosal immunity (secretory-IgA), F-serum immunoglobulins (IgA, IgM \& IgG), G-antihypertensive activity.

\section{Separation and purification.}

It has been reported that the molecular weight of most immunomodulatory peptides were less than $2 \mathrm{kDa}$, so the separation and purification of immunomodulatory peptides play an important role in analyzing immunomodulatory peptides activity. Milda obtained peptides of less than $3 \mathrm{kDa}$ with significantly decreased the basal nuclear factor (NF)- $\kappa \mathrm{B}$ activity in Caco-2 cells through Ultracel regenerated cellulose ultrafiltration membrane [17]. Chromatographic separation, especially high-performance liquid chromatography (HPLC), and gel electrophoresis were also widely used in the separation and purification of immunomodulatory peptides, but the HPLC was more effective than gel electrophoresis when be used in industry because of different throughput and costing.

\section{The mechanism of immunomodulation}

It is well-known that the composition of amino acid, sequence and special structure influences the immunomodulation of protein peptides. So the factors influenced immunomodulatory activities have aroused increasing interests among researchers. Bioactive peptides were composed of 3 to 20 amino acids and have a positive impact on human health. As show in Table 2, immunomodulatory peptides are usually consist of hydrophobic amino acid, such as Ala, Val, Met, Ple, Ile, Leu, Pro, Trp, is in agreement with report of Easton. However, it has been postulated that overall ability of immunomodulatory must be attributed to comprehensive effects of a lot of factors rather than to the individual effect of the hydrophobicity of amino acid. Three structurally related small molecular weight peptides with limited sequence similarity to frenatin were compared and demonstrated to the C-terminal $\alpha$-amidation, which plays an important role in immunoregulation [18]. It also has been observed that lower molecular weight and positively charged peptides plays the key role when it stimulated lymphocyte proliferation at much lower concentration [19]. 
Table 2 Amino acid compositions and their immunomodulatory activity

\begin{tabular}{|c|c|c|c|}
\hline Source of peptides & Amino acid sequence & Activity & References \\
\hline Bursa of Fabricius & $\begin{array}{l}\text { ALPVVVII } \\
\text { DRATHGGE } \\
\text { GANEVEEER }\end{array}$ & $\begin{array}{l}\text { increased the numbers of cfu } \\
\text { pre-b, enhanced aiv-specific } \\
\text { antibody and cytokine production }\end{array}$ & [20] \\
\hline $\begin{array}{l}\text { Alaska pollock } \\
\text { Frame protein }\end{array}$ & $\begin{array}{l}\text { Tyr-Gly } \\
\text { Asn-Gly-Met-Thr-Tyr } \\
\text { Asn-Gly-Leu-Ala-Pro }\end{array}$ & $\begin{array}{l}\text { lymphocyte proliferation rates } \\
\text { were improved to } 35.92 \% \text {, } \\
32.96 \% \text {, and } 31.35 \% \text {,respectively }\end{array}$ & [11] \\
\hline Soy protein & $\begin{array}{l}\text { His-Cys-Gln-Arg-Pro-Arg } \\
\text { Gln-Arg-Pro-Arg }\end{array}$ & $\begin{array}{l}\text { exhibitd phagocytosis stimulatory } \\
\text { effect }\end{array}$ & [8] \\
\hline Skin secretions & $\begin{array}{l}\text { GLVGTLLGHIGKAILG.NH2(2. } \\
\text { 1S) } \\
\text { GLVGTLLGHIGKAILS.NH2(2. } \\
\text { 2S) } \\
\text { GLVGTLLGHIGKAILG(2.3S) }\end{array}$ & $\begin{array}{l}2.1 \mathrm{~s}\left(\mathrm{lc}_{50}=80 \pm 6 \mu \mathrm{m}\right) \text { and } 2.2((\mathrm{lc} 50 \\
=75 \pm 5 \mu \mathrm{m}) \text { for cytotoxic against } \\
\text { non-small cell but less hemolytic } \\
\text { against human erythrocytes }\end{array}$ & [18] \\
\hline
\end{tabular}

Today, more and more people try to synthesis peptides identified as potential modulators of immune system function and selected on the basis of physicochemical characteristics [21]. On one hand, the chemical synthesized peptides could replace the matrix peptides to evaluate the immunomodulating properties. It also can be explored the mechanism of modulate immune response was also explored. More and more advanced technologies have been used to explore the mechanism of immunoregulation like HPLC. The peptides charge, hydrophobicity and the length of peptide chain have great influences on the immunomodulating activity of peptides [19].

\section{Summary}

An increasing number of immunomodulating peptides are prepared by enzymatic hydrolysis from all kinds of natural resources. However, we only know that immunomodulating peptides from natural proteins could modulate immune system but the mechanism of modulate immune system through protein peptides was rarely showed. As the application of immunomodulating peptides are widely used in preventing and inhibiting the proliferation of pathogenic bacterium, it becomes an urgent mission for us to reveal the mechanism of immunoregulation.

\section{Acknowledgements}

The authors acknowledge the financial support provided by the Key Projects of Jilin province Science \& Technology Program (20150204032NY) and the Youth Scientific Innovation Leading Talent and Team Building Project of Jilin Province (20140519014JH).

\section{References}

[1] Anna Iwaniak, Piotr Minkiewicz. Proteins as the source of physiologically and functionally active peptides [J]. Acta Scientiarum Polonorum Technologia Alimentaria, 20076 (3) 5-15.

[2] Jerzy Dziuba, Anna Iwaniak, Piotr Minkiewicz. Computer-aided characteristics of proteins as potential precursors of bioactive peptides [J]. Polimery, 200348 (1) 50-53.

[3] Jean-François Mallet, Jairo Duarte, Gabriel Vinderola, Raphaël Anguenot, Martin Beaulieu, Chantal Matar. The immunopotentiating effects of shark-derived protein hydrolysate [J]. Nutrition, 201430 (6) 706-712. 
[4] Hongxiang Sun, LiQing Chen, Juan Zhang, Fengyang Chena, Anti-tumor and immunomodulatory activity of peptide fraction from the larvae of Musca domestica [J]. Journal of Ethnopharmacology, 2014153 (3) 831-839.

[5] Lin Yang, Jiao Yuan, Zhiguang Zhou. Emerging Roles of Dipeptidyl Peptidase 4 Inhibitors: Anti-Inflammatory and Immunomodulatory Effect and Its Application in Diabetes Mellitus [J]. Canadian Journal of Diabetes, 201438 (6) 473-479.

[6] Jolles P, Parker F, Floc'H F, Migliore, D; Alliel, P; Zerial, A; Werner, G H. Immunostimulating substances from human casein.[J]. Journal of Immunopharmacology, 19813 (3-4) 363-9.

[7] Dominic Agyei, Michael K Danquah. Rethinking food-derived bioactive peptides for antimicrobial and immunomodulatory activities[J]. Trends in Food Science \& Technology, 201223 (2) 62-69.

[8] Brij Pal Singh, Shilpa Vij, Subrota Hati. Functional significance of bioactive peptides derived from soybean [J]. Peptides, 201454 (2) 171-179.

[9] Sylvie F. Gauthier , Yves Pouliot, Diane Saint-Sauveur. Immunomodulatory peptides obtained by the enzymatic hydrolysis of whey proteins [J]. International Dairy Journal, 200616 (11) 1315-1323.

[10] M. Chalamaiah , R. Hemalatha, T. Jyothirmayi, Prakash V. Diwan, P. Uday Kumar, Chetan Nimgulkar, B. Dinesh Kumar. Immunomodulatory effects of protein hydrolysates from rohu (Labeo rohita) egg (roe) in BALB/c mice [J]. Food Research International, 201462 (8) 1054-1061.

[11] $\mathrm{Hu}$ Hou, Yan Fan, Bafang Li, Changhu Xue, Guangli Yu, Zhaohui Zhang ; Xue, Zhao.Purification and identification of immunomodulating peptides from enzymatic hydrolysates of Alaska Pollock frame [J]. Food Chemistry, 2012134 (2) 821-828.

[12] Jingjiao Ma, Xueying Mao, Qianwang, Shu Yang, Dan Zhang, Shangwu Chen, Yinghui Li. Effect of spray drying and freeze drying on the immunomodulatory activity, bitter taste and hygroscopicity of hydrolysate derived from whey protein concentrate [J]. LWT-Food Science and Technology, 201456 (2) 296-302.

[13] Xiangzhen Kong, Mingming Guo, Yufei Hua, Dong Cao, Caimeng Zhang. Enzymatic preparation of immunomodulating hydrolysates from soy proteins [J]. Bioresource Technology, 200899 (18) 8873-8879.

[14] Yukai Wang, Hailun He, Guofan Wang, Hao Wu, Baicheng Zhou, Xiulan Chen, Yuzhong Zhang. Oyster (Crassostrea gigas) Hydrolysates Produced on a Plant Scale Have Antitumor Activity and Immunostimulating Effects in BALB/c Mice[J]. Marine Drugs, 2010, 8(2):255-268.

[15] Feng Lin, Liang Chen, Rui Liang, Zhaofeng Zhang, Junbo Wang, Muyi Cai, Yong Lia. Pilot-scale production of low molecular weight peptides from corn wet milling byproducts and the antihypertensive effects in vivo and in vitro [J]. Food Chemistry, 2011124 (3) 801-807.

[16] Humberto J. Morris, Olimpia Carrillo, Angel Almarales, Rosa C. Bermúdez, Yamila Lebeque, Roberto Fontaine, Gabriel Llauradó, Yaixa Beltrán. Immunostimulant activity of an enzymatic protein hydrolysate from green microalga Chlorella vulgaris on undernourished mice [J]. Enzyme Microbal Technology, 200740 (3) 456-460.

[17] Milda Stuknyte, Ivano De Noni, Simone Guglielmetti, Mario Minuzzo, Diego Mora. Potential immunomodulatory activity of bovine casein hydrolysates produced after digestion with proteinases of lactic acid bacteria[J]. International Dairy Journal, 201121 (10) 763-769.]

[18] J. Michael Conlon, Milena Mechkarska, Gordana Radosavljevic, Samir Attoub, Jay D. King, Miodrag L. Lukic, Stephen McClean. A family of antimicrobial and immunomodulatory peptides 
related to the frenatins from skin secretions of the Orinoco lime frog Sphaenorhynchus lacteus (Hylidae) [J]. Peptides, 201456 132-140.

[19] Amélie Mercier, Sylvie F. Gauthier, Ismaïl Fliss. Immunomodulating effects of whey proteins and their enzymatic digests [J]. International Dairy Journal, 200414 (3) 175-183.

[20] Xiaodong Liu, Bin Zhou, Ruibing Cao, Xiuli Feng, Xinfeng Li, Puyan Chen. Comparison of immunomodulatory functions of three peptides from the chicken bursa of Fabricius [J]. Regulatory Peptides, 2013 186(3) 57-61.

[21] Arnaud Jacquot, Sylvie F Gauthier, Rejean Drouin, Yvan Boutin. Proliferative effects of synthetic peptides from $\beta$-lactoglobulin and $\alpha$-lactalbumin on murine splenocytes [J]. International Dairy Journal, 2010, 20(8):514-521. 